\title{
Meltwater production in Antarctic blue-ice areas: sensitivity to changes in atmospheric forcing
}

\author{
Glen E. Liston, Oddbjørn Bruland, Jan-Gunnar \\ Winther, Hallgeir Elvehøy \& Knut Sand
}

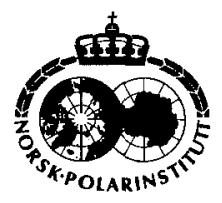

\begin{abstract}
In the near coastal regions of Dronning Maud Land, Antarctica, below-surface icemelt in blue-ice areas has been observed. The low scattering coefficients of the largegrained blue-ice allow penetration of solar radiation, thus providing an energy source below the ice surface. The sub-surface meltwater is significant enough to show up on remote-sensing imagery in the form of ice-covered lakes. Adjacent snow-accumulation areas have much higher scattering coefficients and consequently limit solar radiation penetration in these regions. These snow and ice surfaces are generally below freezing, and little surface melting occurs. To assess the response of these melt features to changes in atmospheric forcings such as cloudiness, air temperature, and snow accumulation, a physically-based model of the coupled atmosphere, radiation, snow, and blue-ice system has been developed. The model consists of a heat transfer equation with a spectrally-dependent solar-radiation source term. The penetration of radiation into the snow and blue-ice depends on the surface albedo, and the snow and blue-ice grain size and density. Model simulations show that ice melt occurring in this area is sensitive to potential variations in atmospheric forcing. Under certain conditions more traditional surface melting occurs and, under other conditions, the existing melt processes can be shut down completely. In light of the sensitivity of this system to variations in atmospheric forcing, and the ability to view melt-related features using remote sensing, a tool exists to efficiently monitor variations in Antarctic coastal climate.
\end{abstract}

G. E. Liston, Dept. of Atmospheric Science, Colorado State University, Fort Collins, CO, 80523 USA; O. Bruland \& K. Sand, SINTEF Norwegian Hydrotechnical Laboratory, N-7034 Trondheim, Norway; J.-G. Winther, Norwegian Polar Institute, Polar Environmental Centre, N-9296 Troms $\phi$, Norway; H. Elvehфy, Norwegian Water Resources and Energy Administration, N-0301 Oslo, Norway.

\section{Introduction}

In the near coastal blue-ice regions of Dronning Maud Land, Antarctica, below-surface ice-melt features have been regularly observed during recent Norwegian Antarctic Research Expeditions (NARE) to an area called Jutulgryta, located at $71^{\circ} 24^{\prime} \mathrm{S}, 0^{\circ} 31^{\prime} \mathrm{E}$, at an elevation of approximately $150 \mathrm{~m}$ (Fig. 1) (Winther et al. 1996). The Jutulgryta area consists of gently rolling ice topography having ridge-to-valley distances of 1 to $4 \mathrm{~km}$, with ridge-to-valley heights of approximately $100 \mathrm{~m}$. The region experiences strong and persistent easterly winds that generally keep the blue-ice surfaces swept free of winter snow accumulations (Takahashi et al. 1988; van den
Broeke \& Bintanja 1995a; Liston et al. in press). These blue-ice areas have important physical characteristics that influence the local surface energy balance, meteorology and climate (Bintanja \& van den Broeke 1994; van den Broeke \& Bintanja 1995b; Bintanja et al. 1997). The combination of easterly winds and rolling ice surface topography leads to snowdrift accumulation zones that form in the lee of the ice hills during winter. These snow-covered regions are found adjacent to the blue-ice fields in the form of bands 500 to $1000 \mathrm{~m}$ wide and several kilometres long, and cover about $30 \%$ of the area (Winther et al. 1996; Liston et al. 1999).

The blue-ice areas of this region continually experience below-surface melting during the 


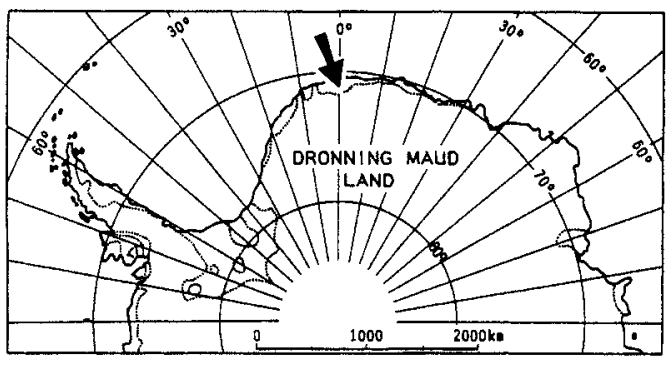

Fig. 1. Location of the Norwegian Antarctic Research Expedition (NARE) study area in Jutulgryta, Dronning Maud Land, Antarctica.

summer months; this generally occurs while the air, snow and ice surface temperatures are below freezing. The sub-surface melting can be explained largely by the interactions between the snow-ice-water matrix and the near surface radiation and energy balances. The low scattering produced by the relatively large-grained blue-ice allows short-wave solar radiation to penetrate the ice, thus providing a heat source below the ice surface that is sufficient to warm and melt the ice. The meltwater produced by this mechanism drains within the blue-ice matrix and accumulates in lakes which drain both from distinct discharge channels and through the ice below. These meltwater accumulation lakes can be a few kilometres across and are of sufficient size to show up on LANDSAT and ERS imagery (Winther 1993; Winther et al. 1996). Nearly all of the observed melting activity in the blue-ice areas occurs at least $15 \mathrm{~cm}$ below the typically frozen upper surfaces. Adjacent snow accumulation areas have much higher scattering coefficients and consequently limit solar radiation penetration and sub-surface melt.

To help describe and explain the differences in melt-related features observed in the blue-ice and snow-covered areas of Jutulgryta, a physically based numerical model of the coupled atmosphere, radiation, snow, and blue-ice system was developed (Liston et al. 1999). The model consists of a one-dimensional time-varying heat transfer equation that includes a spectrally dependent solar radiation source term. The penetration of radiation into snow and blue-ice depends on the solar radiation spectrum, the surface albedo, and the snow and blue-ice grain sizes and densities. The model is run over the full annual cycle, simulating temperature profiles and melting and freezing quantities throughout the summer and winter seasons. In this paper, the model is used to address the sensitivity of this below-surface melt to variations in atmospheric forcing.

\section{Model description}

A detailed description of the model equations and the solution procedures can be found in Liston et al. (1999). The physically based model has been formulated to describe the one-dimensional, time dependent temperature and melting distributions within a snow or ice cover that allows solar radiation penetrating into its upper layers. The formulation relies heavily on the methods of Schlatter (1972), who developed a model to study the sub-surface temperature and melt profiles in Antarctica using a broad-band (spectrally independent, and constant with depth) solar radiation extinction coefficient. In addition, the formulation makes strong use of the techniques developed by Brandt \& Warren (1993), who modified Schlatter's methodology to include the spectral dependence of solar radiation penetrating snow and ice.

Energy is transferred through the snow-icewater matrix by conduction along grain boundaries, and by vapor diffusion along pore spaces. In addition, this problem requires a solar radiative energy source term that varies with depth. The general ice temperature distribution and temporal evolution is described by the following onedimensional heat transfer equation:

$$
\rho_{i} C_{p} \frac{\partial T_{i}}{\partial t}=\frac{\partial}{\partial z}\left(\left(k_{i}+k_{v}\right) \frac{\partial T_{i}}{\partial z}\right)-\frac{\partial q}{\partial z}
$$

where $T_{i}$ is the snow-ice temperature, $z$ is the vertical coordinate, $t$ is time, $\rho_{i}$ is the snow-ice density, $C_{p}$ is the specific heat of the snow-ice, and $q$ is the solar radiative flux. The thermal conductivity of the snow-ice matrix, $k_{i}$, is given by (Sturm et al. 1997), and the latent heat flux coefficient, $k_{v}$, that accounts for water-vapor diffusion within the air passageways, is defined following Schlatter (1972). The radiation flux penetrating the snow or ice, $q$, is computed using a two-stream approximation, as does Schlatter (1972). The dependence of this radiation flux on the solar radiation spectrum and the snow-ice density and grain size, is defined following Brandt \& Warren (1993).

The solution of Equation (1) requires upper and 


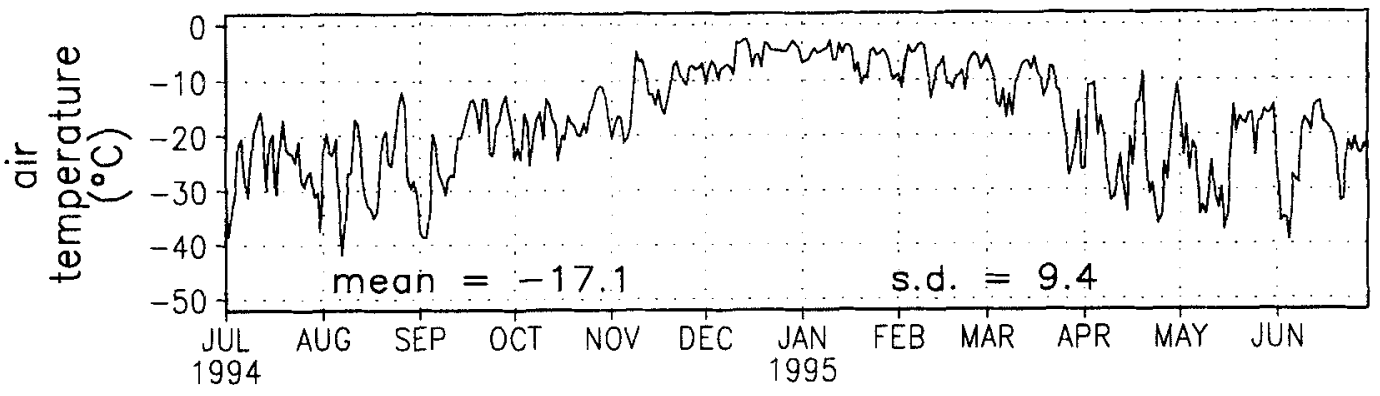

Fig. 2. Observed air temperature forcing used in the model simulations. Data collected at the Neumayer Antarctic research station and made available as part of the World Meteorological Organization (WMO) World Weather Watch Program.

lower boundary conditions, and initial conditions. The upper boundary condition is determined by performing a full energy balance at the surface, and for the lower boundary a zero temperature gradient condition is imposed at a depth of $15 \mathrm{~m}$ (Liston et al. 1999). For each of the simulations considered in this paper. initial conditions throughout the profile are given by imposing a constant profile equal to the mean annual air temperature, and then integrating the model, starting on 1 July, for five years; by this time the deepest ice temperatures have reached equilibrium. The model integration is then continued for one additional year, and those results are presented herein.

\section{Model simulations}

In what follows, the general solution of the model equations will be described, and the model results will be validated against observations collected during NARE 1996/97. The first two simulations will be referred to as "control" simulations, where one control simulation is performed for blue-ice conditions and the other is performed for snow conditions. Then the model will be used to assess the sensitivity of the melt features to variations in atmospheric forcing. A more complete discussion of the model validation can be found in Liston et al. (1999).

\section{Validation simulations}

To solve the model's system of equations, additional information is required in the form of atmospheric forcing data, snow and blue-ice property data, and the distributions of parameters describing the interaction between snow and ice grains and solar radiation. The distributions of subsurface solar radiation scattering parameters vary according to wavelength and snow/ice grain size (Wiscombe \& Warren 1980). In addition, the downward solar radiation spectrum reaching the surface must be known, and is defined by output from the Stackhouse \& Stephens (1991) twostream, 256 spectral-band, atmospheric radiation model.

Atmospheric forcing data of air temperature, relative humidity and wind speed are also required to complete the full annual integrations. These were obtained from the relatively nearby Neumayer (German) research station, located at $70^{\circ} 40^{\prime} \mathrm{S}, 8^{\prime} 15^{\prime} \mathrm{W}$, at an elevation of approximately $40 \mathrm{~m}$ (the Jutulgryta research site is approximately $85 \mathrm{~km}$ north, $315 \mathrm{~km}$ east, and $110 \mathrm{~m}$ higher than the Neumayer station). Comparison of 1994-95 data from this station with the limited summer meteorological data collected at Jutulgryta suggests that the Neumayer data set is fairly representative of Jutulgryta's atmospheric conditions (Liston et al. 1999). The only adjustment made to the Neumayer data was to reduce the air temperatures by $1 \mathrm{C}$ to account for the elevation difference. The 365-day, daily averaged screenheight air temperature record used to drive the model simulations is provided in Fig. 2 (for relative humidity and wind speed data, see Liston et al. 1999). In this record, the air temperature and wind speed show a strong seasonal cycle and the air temperatures are continuously below freezing. To solve the surface energy balance, the cloud cover fraction is also required as input. Since this input was unknown, it was used as a parameter that could be modified to vary the amount of solar 
Table 1. Snow and ice property data used in the model simulations.

\begin{tabular}{lcc}
\hline & Snow & Blue-ice \\
\hline Broad-band albedo & 0.75 & 0.65 \\
Grain radius (mm) & 0.35 & 5.00 \\
Density $\left(\mathrm{kg} \mathrm{km}^{-3}\right)$ & 550 & 800 \\
\hline
\end{tabular}

radiation reaching the snow/ice surface. In the control simulations a temporally constant cloud fraction of 0.5 was used.

Snow and ice property values of albedo, density and grain size are also required by the model. Field observations during NARE 1996/97 are used to supply this information; the values used in the model simulations are summarized in Table 1. Applying these different values of density. grain radii, and albedo for snow and blue-ice is the only difference between the snow and blue-ice control simulations. Inputs of surface albedo, density and grain radii for snow and blue-ice allow computation of the solar energy flux variation with depth within the snow and blue-ice (see figure 10 in Liston et al. 1999).

Solution of Equation (1) produces temperature and water fraction distributions within the snow and blue-ice mediums. See figure 12 in Liston et al. (1999) for a comparison of mid-January snow and blue-ice observations and model simulated temperature profiles. In addition, as part of the model solution the fraction of water contained within each computational grid cell is accounted for. For the control simulations, maximum water fractions of 0.25 and 0.03 are simulated for blueice and snow, respectively (see figure 13 in Liston et al. 1999).

\section{Sensitivity simulations}

Using the same snow and ice property values used in the validation (control) simulations (Table 1), eight additional sensitivity simulations were performed. Four of these were for changes to the observed air temperature given in Fig. 2, and the other four were for changes to the control cloud fraction. In the model, increasing (decreasing) the cloud fraction leads to decreases (increases) in solar and increases (decreases) in longwave radiation reaching the surface. These changes in atmospheric conditions are summarized in Table 2. The temperature changes were applied while using the control cloud fraction $(0.5)$, and the
Table 2. Atmospheric values used in model sensitivity simulations.

\begin{tabular}{cc}
\hline $\begin{array}{c}\text { Temperature } \\
\text { change }(\text { "C) }\end{array}$ & $\begin{array}{c}\text { Cloud } \\
\text { fraction }\end{array}$ \\
\hline+6.0 & 0.1 \\
+3.0 & 0.3 \\
$0.0($ control $)$ & 0.5 (control) \\
-3.0 & 0.7 \\
-6.0 & 0.9 \\
\hline
\end{tabular}

cloud fraction changes were applied while using the observed air temperature given in Fig. 2. Under current climate conditions (the control simulations), the majority of the sub-surface melting occurs in the blue-ice areas, with only minimal melting found in the snow areas. In the discussions that follow, both snow and blue-ice sensitivities will be presented. This is done under the assumption that the snow case represents conditions that would occur if snow accumulation were to increase and cover portions of the blue-ice areas.

The variation in snow and ice temperatures in the top $3 \mathrm{~m}$ of the domain, in response to the changes in air temperature, are given in Fig. 3. This is the 16 January profile, chosen because the middle of January yields the maximum snow and ice temperatures. The thick line is the control simulation and the two lines on the right and left sides of it correspond to the air temperature increases and decreases, respectively (for all subsequent figures the thick line in the plots will correspond to the control simulation). For the case of the $+6^{\circ} \mathrm{C}$ air temperature change, both the snow and blue-ice become isothermal $\left(0^{\circ} \mathrm{C}\right)$ at the surface, indicating the potential for traditional surface melting, in addition to the sub-surface melting. The thickness of the isothermal zone has increased with the increasing temperature and decreased for the case of decreasing air temperature. For the snow, the decrease of 3 and $6^{\circ} \mathrm{C}$ has led to the disappearance of the isothermal zone and, for blue-ice, the decrease of $6^{\circ} \mathrm{C}$ has nearly eliminated the isothermal zone. The 16 January meltwater, produced by the air temperature increases, are large for both the snow and blueice, although at its maximum, the depth of meltwater production for the blue-ice is twice that of snow (Fig. 4). For both snow and blue-ice, the $6^{\circ} \mathrm{C}$ temperature increase has produced water fractions of around 0.5 . Such high water fractions are expected to produce collapsing of the snow and 

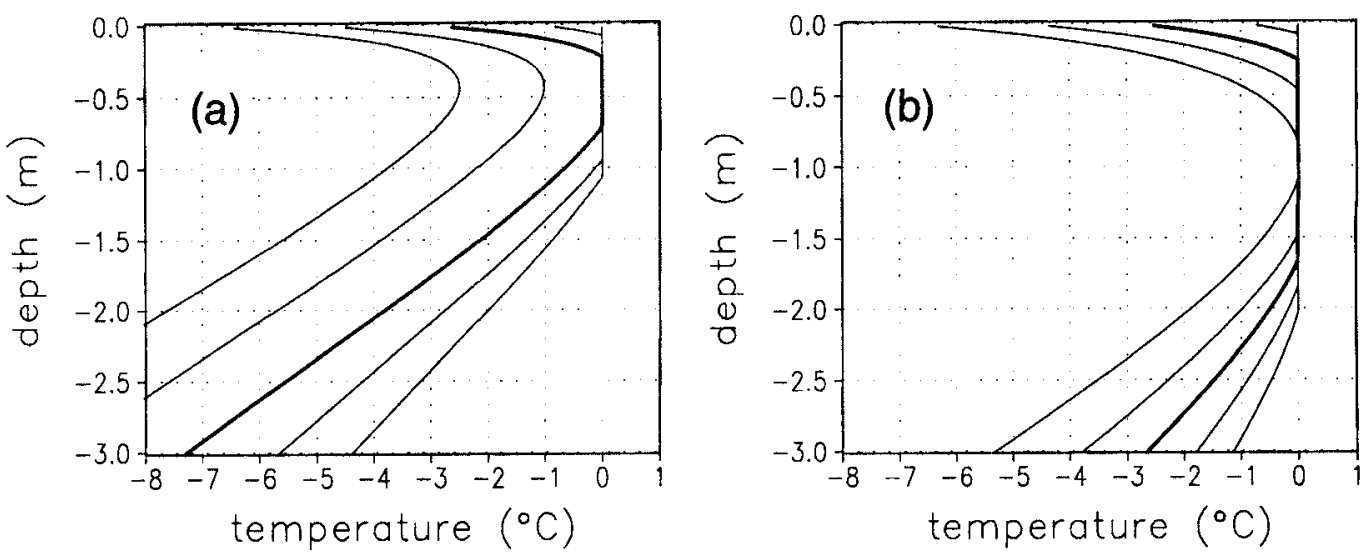

Fig. 3. 16 January temperature profiles for (a) snow and (b) blue-ice, for the case of the air temperature modifications given in Table 2. The thick line is the control simulation and the lines to the right (left) are for the temperature increases (decreases).
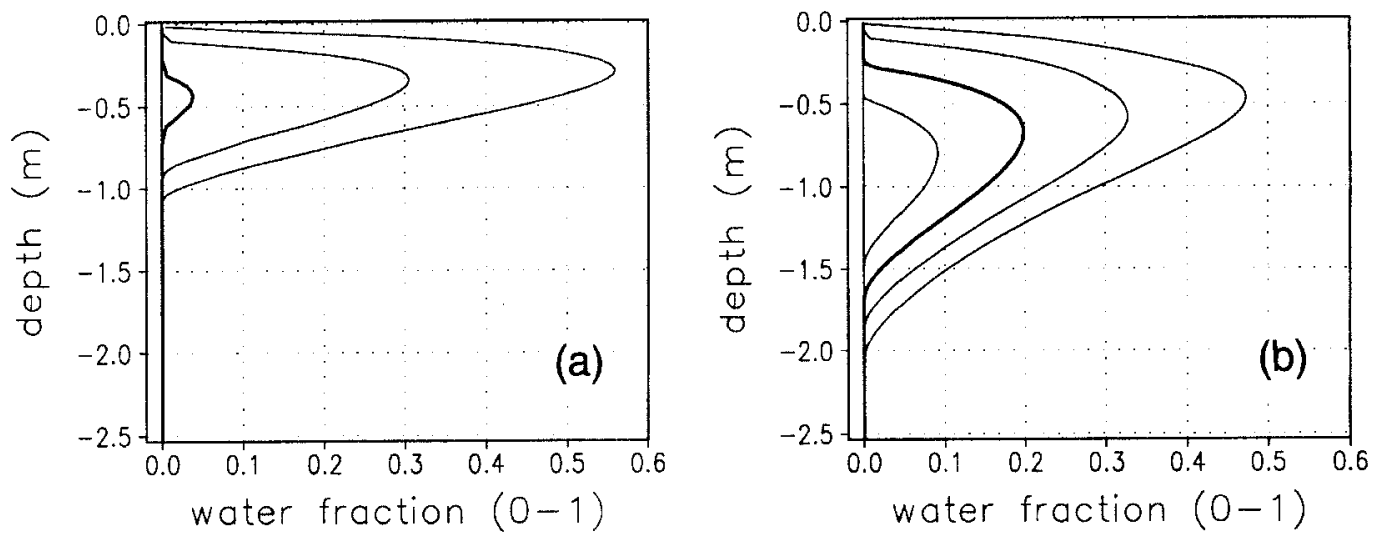

Fig. 4. 16 January water fraction profiles for snow (a) and blue-ice (b), for the case of the air-temperature modifications given in Table 2. The thick line is the control simulation and the lines to the right (left) are for the temperature increases (decreases).
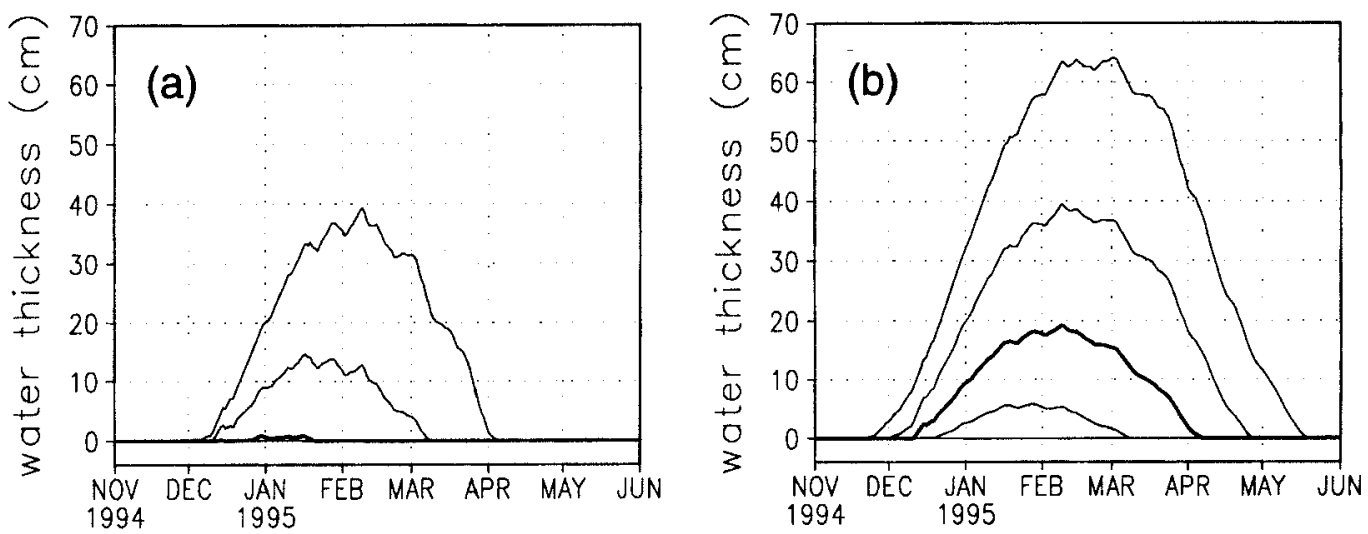

Fig. 5. Total-column water-thickness evolution for snow (a) and blue-ice (b), for the case of the air-temperature modifications given in Table 2. The thick line is the control simulation and the lines above (below) are for the temperature increases (decreases). 
ice surfaces. For the snow case, the 3 and $6^{\circ} \mathrm{C}$ temperature reductions have shut down the production of meltwater. For blue-ice, the $6^{\circ} \mathrm{C}$ air-temperature reduction also produces no meltwater. As another measure of the meltwater variations produced in response to the air temperature changes, the thickness of liquid water, over the total snow or ice column, can be quantified and plotted as it varies over the melt and freeze-up seasons (Fig. 5). The temperature changes modify both the initial water production date and final freeze-up date, leading to a change in "melt season" length of nearly one month per $3^{\circ} \mathrm{C}$ air temperature change. This holds for both snow and blue-ice. In addition, Fig. 5 shows nearly a doubling (halving) of water thickness for every $3^{\circ} \mathrm{C}$ air temperature increase (decrease) for the ranges of temperature variation considered.

For the case of modifying the cloud fraction, the resulting changes in snow and ice temperatures for January 16 are given in Fig. 6. In these simulations, the changes in solar and longwave radiation reaching the surface have roughly balanced, and thus have had little influence on the surface temperature boundary condition. But the change in solar radiation reaching and penetrating the surface does strongly influence the below-surface temperature regimes. The 16 January water fraction variations resulting from cloud fraction changes are given in Fig. 7. For the case of snow, the higher cloud fractions led to no meltwater production, while in blue-ice, even the maximum cloud fraction of 0.9 produces some sub-surface melting. Figure 8 highlights the sensitivity of liquid water thickness to cloud fraction changes. Similar to the air temperature change simulations, the duration of "melt season" can be lengthened or shortened by several weeks in response to the cloud cover changes considered herein. In addition, the water thickness is found to increase (decrease) by a factor of about 0.5 for a cloud cover decrease (increase) of 0.2 .

A unique aspect of this system is production of meltwater within the snow and ice. As shown in the sensitivity simulations, below-surface melting in the blue-ice requires air temperatures within several degrees of freezing. For the snow, belowsurface melting occurs for temperatures within a few degrees of freezing. This meltwater is bounded by sub-freezing layers above and below. In the preceding analyses the below-surface melt has been found to be quite sensitive to the imposed air temperature changes, and less sensitive to the cloud cover changes. The fundamental reason for this sensitivity is that the system is so close to the melt/freeze threshold. Through the surface energy balance, the air temperature has a direct influence on the snow and ice surface temperatures. This is highlighted in Fig. 3, where the surface temperatures show distinct changes for each sensitivity test. In contrast, the temperatures shown in Fig. 6 show that the primary influence of cloud fraction changes are to modify the solar radiation penetrating the surface. This influences the strength of the below-surface solar radiation source term, but has little effect on the snow/ice surface temperatures. In contrast to the simple cloud radiation model used in this study (Liston et al. 1999), the influence of clouds on the surface radiation budget over snow and blue-ice have been found to be complex and depend strongly on the cloud optical properties (Bintanja \& van den Broeke 1996). Unfortunately, the required inputs to drive a more complex cloud radiation model for the region of interest are not available.

\section{Conclusions}

In the near coastal regions of Dronning Maud Land, below-surface ice melting occurs in blue-ice areas that experience strong and persistent winds that generally keep the ice surface swept free of winter snow accumulations. The low scattering coefficients that exist in the relatively largegrained blue ice allow solar radiation to penetrate the ice, thus providing a heat source below the ice surface. Adjacent snow accumulation areas have much higher scattering coefficients and consequently limited solar radiation penetration in these regions. The surface energy balance keeps the surface generally below freezing and little surface melting occurs. In the blue-ice areas, belowsurface meltwater is produced throughout the summer months, while in the nearby snow areas below-surface melting is minimal. The resulting meltwater is significant enough to show up on LANDSAT and ERS remote sensing imagery in the form of ice-covered lakes that develop in relatively low areas of the coastal Antarctic Ice Sheet.

To assess the response of these melt features and processes to changes in important forcings such as cloudiness, air temperature, and snow accumulation, a physically based numerical model of the 

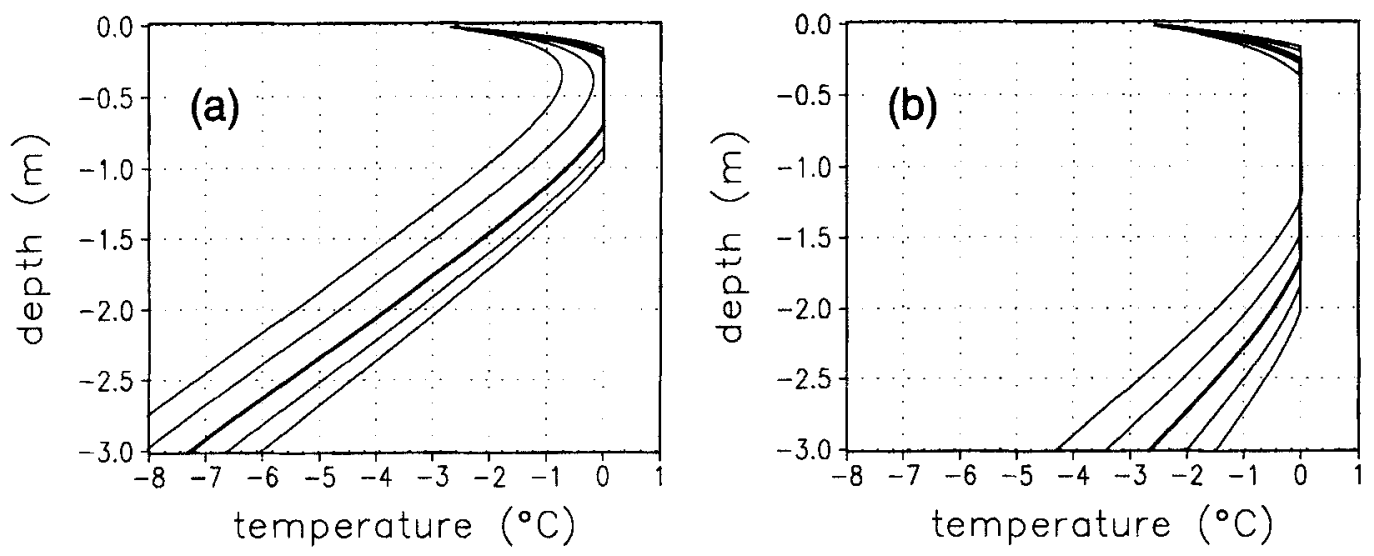

Fig. 6. January 16 temperature profiles for snow (a) and blue-ice (b), for the case of the cloud-fraction modifications given in Table 2. The thick line is the control simulation and the lines to the right (left) are for the cloud-fraction decreases (increases).
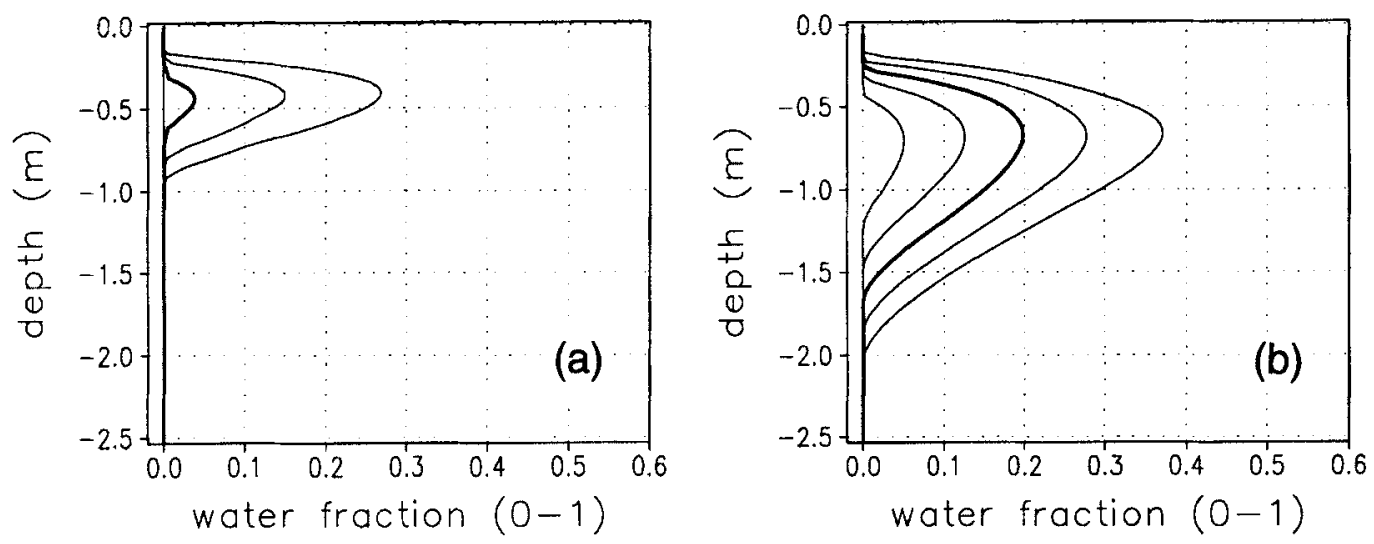

Fig. 7. January 16 water-fraction profiles for (a) snow and (b) blue-ice, for the case of the cloud fraction modifications given in Table 2. The thick line is the control simulation and the lines to the right (left) are for the cloud fraction decreases (increases).
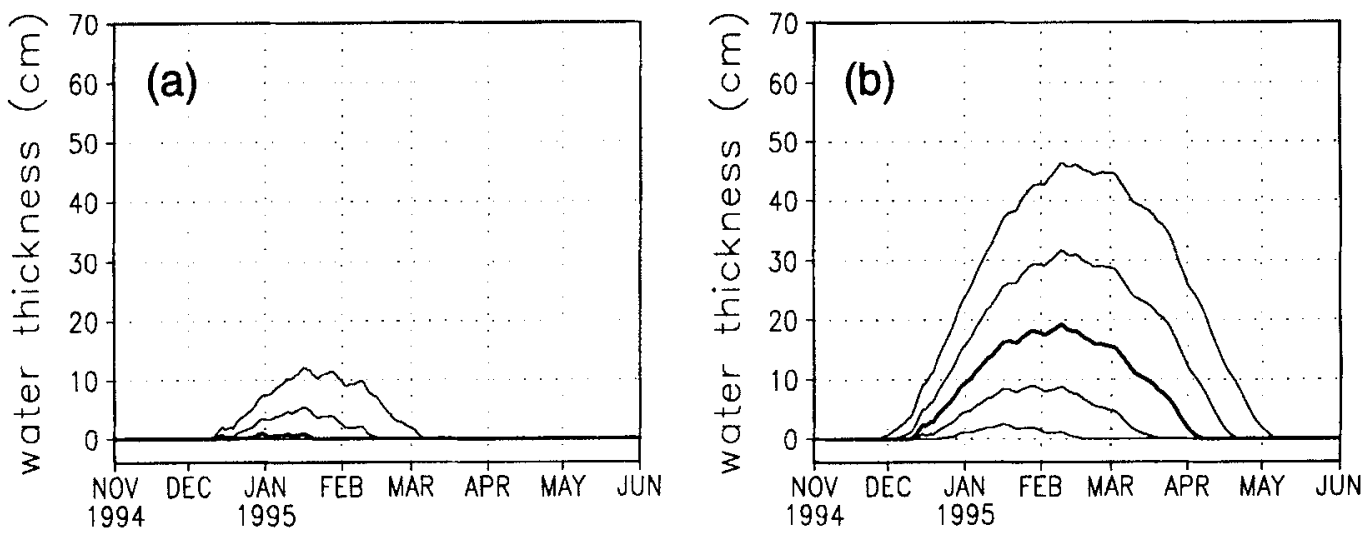

Fig. 8. Total column water thickness evolution for (a) snow and (b) blue-ice, for the case of the cloud fraction modifications given in Table 2. The thick line is the control simulation and the lines above (below) are for the cloud fraction decreases (increases). 
coupled atmosphere, radiation, snow, and blue-ice system has been developed. The model consists of a heat transfer equation which includes a spectrally dependent solar radiation source term. The penetration of radiation into the snow/blue-ice depends on the solar radiation spectral bands and on the snow/blue-ice grain size and density. In addition, the model uses a complete surface energy balance to define the snow/blue-ice surface boundary conditions. This surface energy balance accounting includes the effects of air temperature and humidity, wind speed, incoming solar and longwave radiation, surface albedo, outgoing longwave radiation, cloudiness, sensible and latent energy fluxes, and conductive energy transport into and out of the snow/blue-ice. The model is run over the full annual cycle, simulating temperature profiles and melt quantities throughout the summer and winter seasons.

The ice melt occurring in this area is sensitive to potential variations in atmospheric forcing. Under certain conditions more traditional surface melting occurs and, under other conditions, the existing melt processes can be dramatically reduced or shut down completely. While it is not clear at this time how much of the Antarctic Ice Sheet and ice shelves experience this kind of melting, our findings suggest that conditions are appropriate for it to occur in nearly all Antarctic blue-ice areas where the summer air temperatures are generally within several degrees of freezing. In light of the sensitivity of this system to variations in atmospheric forcing, coupled with the ability to view associated melt-related features using remote sensing imagery, a potential tool exists to monitor efficiently variations in Antarctic coastal climate.

Acknowledgements. - The authors gratefully acknowledge the participants of NARE 1996/97 for their role in making the field programme a success. This is publication no. 155 of the Norwegian Antarctic Research Expeditions. This work was funded by the Norwegian Research Council.

\section{References}

Bintanja, R. \& van den Broeke, M. R. 1994: Local climate, circulation and surface-energy balance of an Antarctic blueice area. Ann. Glaciol. 20, 160-168.

Bintanja, R. \& van den Broeke, M. R. 1996: The influence of clouds on the radiation budget of ice and snow surfaces in Antarctica and Greenland in summer. Int. J. Climatol. 16, $1281-1296$

Bintanja, R., Jonsson, S. \& Knap, W. H. 1997: The annual cycle of the surface energy balance of Antarctic blue ice. $J$. Geophys. Res. 102, 1867-1881.

Brandt, R. E. \& Warren, S. G. 1993: Solar-heating and temperature profiles in Antarctic snow and ice. J. Glaciol. $39,99-110$

Liston, G. E., Winther, J.-G., Bruland, O., Elvehøy, H. \& Sand, K. 1999: Below-surface ice melt on the coastal Antarctic ice sheet. J. Glaciol. 45, 273-285.

Liston, G. E., Winther, J.-G., Bruland, O., Elvebøy, H., Sand, K. \& Karlöf, L. in press: Snow and blue-ice distribution patterns on the coastal Antarctic Ice Sheet. Antarct. Sci.

Schlatter. T. W. 1972: The local surface energy balance and subsurface temperature regime in Antarctica. J. Appl. Meteorol. II, 1048-1062.

Stackhouse, P. W. \& Stephens, G. L. 1991: A theoretical and observational study of the radiative properties of cirrus: results from FIRE 1986. J. Atmos. Sci. 48, 2044-2059.

Sturm, M., Holmgren, J., König, M. \& Morris, K. 1997: The thermal conductivity of seasonal snow. J. Glaciol. $43,26-41$.

Takahashi, S., Naruse, R., Nakawo, M. \& Mac, S. 1988: A bare ice field in east Queen Maud Land, Antarctica, caused by horizontal divergence of drifting snow. Ann. Glaciol. 11 , $156-160$.

van den Broeke, M. R. \& Bintanja, R. 1995a: On the interaction of katabatic wind and blue ice area formation in EastAntarctica. J. Glaciol. 4I, 395-407.

van den Broeke, M. R. \& Bintanja, R. 1995b: Summertime atmospheric circulation in the vicinity of a blue ice area in East Queen Maud Land, Antarctica. Boundary-Layer Meteorol. 72, 411-438.

Winther, J.-G. 1993: Studies of snow surface characteristics by Landsat TM in Dronning Maud Land, Antarctica. Ann. Glaciol. 17, 27-34.

Winther, J.-G., Elvehøy, H. C., Bøggild, C. E., Sand, K. \& Liston, G. E. 1996: Melting, runoff and the formation of frozen lakes in a mixes snow and blue-ice field in Dronning Maud Land, Antarctica. J. Glaciol. 42, 271-276.

Wiscombe, W. J. \& Warren, S. G. 1980: A model for the spectral albedo of snow. I. Pure snow. J. Atmos. Sci. 37, 2712-2733. 